$\begin{array}{cc}\text { International Journal of Advanced Chemistry, } 8(1)(2020) 22-26 \\ \text { International Journal of Advanced Chemistry } \\ \text { SPC } & \text { Website: } w w w . \text { sciencepubco.com/index.php/IJAC } \\ \text { Research paper }\end{array}$

\title{
Validated extractive analytical methods for the estimation of pregabalin in bulk and pharmaceutical dosage form
}

\author{
Poojashree $\mathbf{P}^{1}$, Senthil kumar G $\mathbf{P}^{1}$, Chaithra $\mathbf{R}^{1}$, Vidya D N ${ }^{1}$, Bhadresh D $\mathbf{R}^{1}$, Manojkumar $\mathbf{S}^{1}$ \\ ${ }^{1}$ Department of Pharmaceutical Chemistry, Bharathi College of Pharmacy, Bharathinagara, Mandya dist., Karnataka-571 422, India \\ *Corresponding author E-mail: drsenn78@yahoo.com
}

\begin{abstract}
Two simple, rapid, sensitive and accurate spectrophotometric methods are described for the determination of Pregabalin (PRG) in bulk and pharmaceutical formulations. The methods are based on the reactions of the drug with bromocresol purple (BCP) and bromocresol green (BCG) in buffered hydrochloric acid solutions at $\mathrm{pH} 1.2$ to give coloured ion-pair complexes extractable with chloroform. The coloured products are quantitated spectrophotometrically at $431 \mathrm{~nm}$ with BCP and $444.80 \mathrm{~nm}$ with BCG. Beer's law is obeyed in the concentration range $10-50 \mu \mathrm{g} / \mathrm{ml}$ with both reagents. Recovery studies gave satisfactory results indicating that none of common additives and excipients interfere the assay method. The proposed methods are found to be simple, accurate and reproducible that was successfully applied for the analysis of capsule formulations. The developed methods are easy to use, accurate and highly cost-effective for routine studies relative to HPLC and other techniques.
\end{abstract}

Keywords: Bromocresol Green (BCG); Bromocresol Purple (BCP); Ion-Pair Complex; Pregabalin; Spectrophotometric.

\section{Introduction}

Pregabalin (PRG) is chemically (S)-3-(amino methyl)-5-methyl hexanoic acid and is not official in any pharmacopoeia. Structural analogues of $\gamma$-amino butyric acid (GABA) as shown in (Fig.1). Nature of PRG is a new anticonvulsant and analgesic medication that was recently approved for adjunctive treatment of partial seizures in adults for the treatment of neuropathic pain from postherpetic neuralgia and diabetic neuropathy. The site of action of drug is the alpha 2-delta $(\alpha 2-\delta)$ protein, an auxiliary subunit of voltage gated calcium channels. PRG subtly reduces the synaptic release of several neurotransmitters, apparently by binding to $\alpha 2-\delta$ subunit and possibly accounting for its action invivo to reduce neuronal excitability and seizures. A literature survey regarding PRG revealed that attempts were made to develop analytical methods for PRG using extractive spectrophotometric and spectroflurimetric [1-2], LC method with precolumn derivatisation with marfeys reagent [3], HPLC analysis of PRG in human serum [4], Liquid chromatography - mass spectrophotometric (LC-MSMs) [5-7], Heteroaromatic analogs of Pregabalin and its activity on mouse model [8], method had been reported. All of these methods are very expensive because these methods require long and tedious pretreatment of the samples and derivatisation for the analysis of PRG. There is no any economic spectrophotometric method for the analysis of PRG. So there is need for the development of a spectrophotometric method for the analysis of PRG. Hence, an attempt has been made to develop a simple, Quick, Specific, Accurate efficient and selective method for the analysis of PRG in bulk and pharmaceutical formulations. The present study describes two visible extractive spectrophotometric methods for the determination of PRG through ion pair complex formation using bromocresol purple (BCP) and bromocresol green (BCG) as the dye reagents. The developed methods have been applied to determine the drug in capsule.<smiles>CC(C)CC(CN)CC(=O)O</smiles>

Fig. 1: Structure of Pregabalin.

\section{Experimental}

\subsection{Instrument}


A Shimadzu Model No-1800, UV-visible spectrophotometer with $1 \mathrm{~cm}$ matched quartz cells were used for absorbance measurements. $\mathrm{pH}$ Measurements were made with a Digital pH- meter, Toshniwal instrument manufacture Pvt. Ltd (Mumbai, India).

\subsection{Reagents}

All chemicals and reagents were of analytical grade. PRG was obtained from Sun Pharmaceuticals ltd. Mumbai. Neugaba (Sun Pharmaceuticals ltd. Mumbai.) and Gabafit-75 (Glenmark Pharmaceutical Ltd., Mumbai, India) capsules were brought from local pharmacy shops. The reagents BCP and BCG were purchased from E-Merck, Mumbai, India. Distilled water was used to prepare all solutions.

\subsection{Solutions}

The standard solution of PRG $(100 \mu \mathrm{g} / \mathrm{m} 1)$ was prepared in methanol. The reagents of BCP $(0.05 \%)$ and BCG $(0.05 \%)$ dyes were prepared, and Hydrochloric acid buffer of $\mathrm{pH} 1.2$ was also prepared [9]. Required $\mathrm{pH}$ was adjusted using a $\mathrm{pH}$ meter and then the volume was brought to $100 \mathrm{ml}$ with water.

\subsection{Assay procedure for pure drug}

For both methods, accurate aliquots containing 10-50 $\mu \mathrm{g} / \mathrm{ml}$ of PRG were transferred into series of $10 \mathrm{ml}$ volumetric flask. Then $3 \mathrm{ml}$ of HCL acid buffer (pH 1.2 for BCP and BCG methods) and $2 \mathrm{ml}$ of dye solutions were added and mixed. Volume was made up to $10 \mathrm{ml}$ with distilled water. Then transferred into series of separating funnels $(60 \mathrm{ml})$. Each mixture was extracted with $10 \mathrm{ml}$ of chloroform by shaking with vortex for $2 \mathrm{~min}$. Absorbances of the yellow coloured organic layers were measured at $431 \mathrm{~nm}$ and $444.80 \mathrm{~nm}$ for BCP and BCG methods, respectively against a reagent blank prepared similarly. Calibration curves were constructed using the measured absorbances. The linearity was found to be between 10 to $50 \mu \mathrm{g} / \mathrm{ml}$, which is shown in fig. 2 and 3 , respectively.

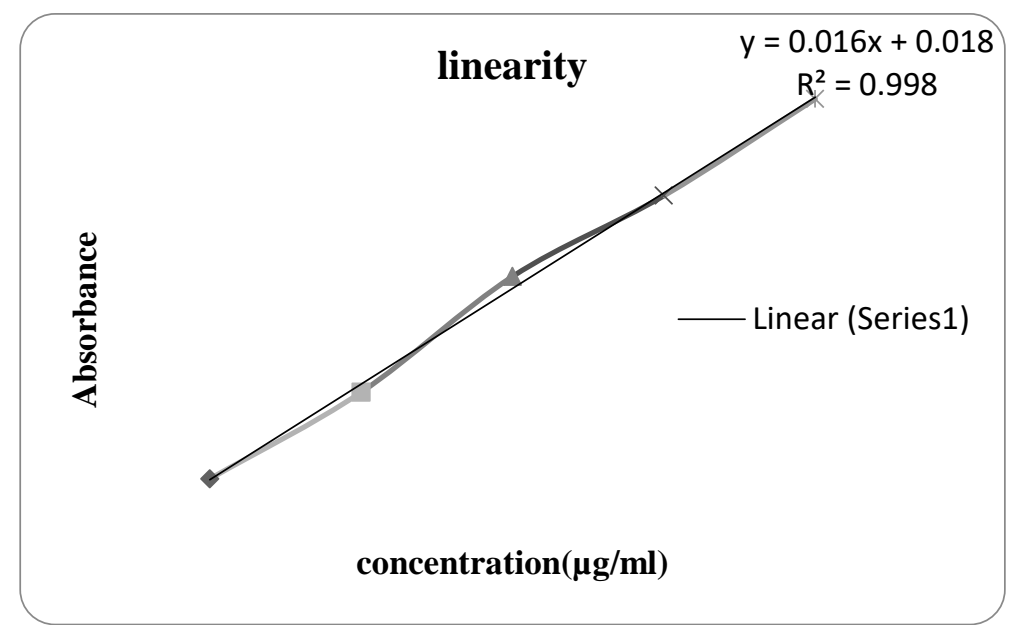

Fig. 2: Linearity of PRG with BCP.

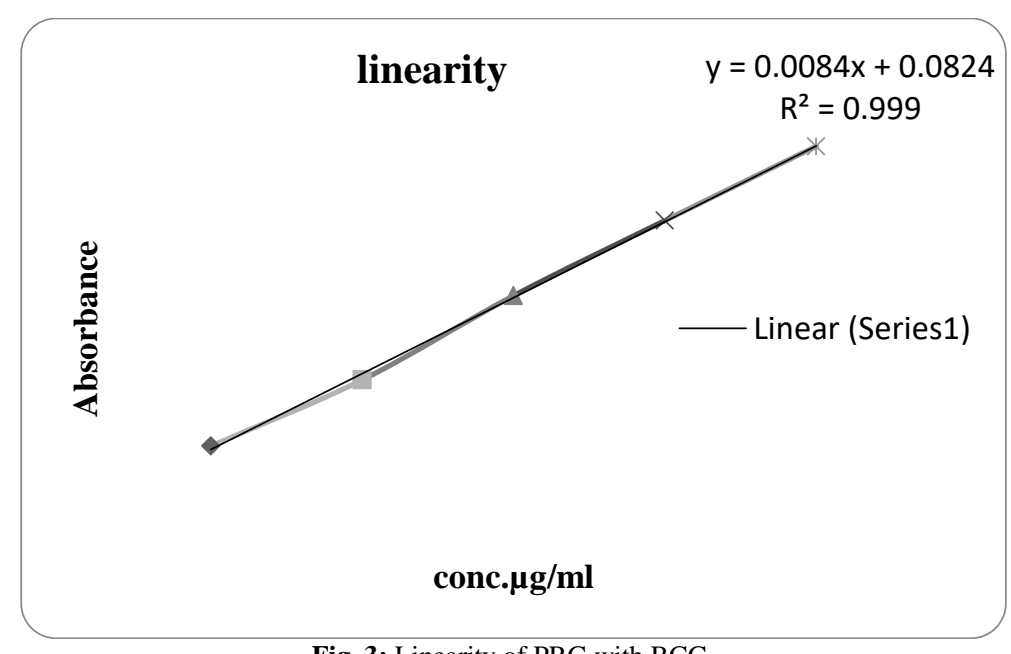

Fig. 3: Linearity of PRG with BCG.

\subsection{Assay procedure for capsules}

20 capsules were weighed without shells and powdered. An accurate amount of the powder equivalent to $25 \mathrm{mg}$ of PRG was transferred into a $25 \mathrm{ml}$ calibrated flask and $15 \mathrm{ml}$ of methanol was added. The mixture was sonicated in an ultrasonic bath for $10 \mathrm{~min}$, and then was adjusted to volume with water, mixed and filtered. Suitable aliquots were subjected to the analysis following the procedure described above. The concentration of PRG was calculated from the corresponding regression equation. 
Condition under which reaction of PRG with dyes fulfills the essential requirements was investigated. All conditions studied were optimized at room temperature $\left(28 \pm 2^{\circ} \mathrm{C}\right)$.

\subsection{Optimization of dye concentrations}

In the study, optimum experimental conditions were first determined. Since the concentration of dye is important for the reactions, different concentration of dye solutions in the range 1-7 ml were tested and $2 \mathrm{ml} \mathrm{BCP}$ dye concentration was found to be the optimum values for BCP and BCG methods, respectively (Fig.4 and 5). Then absorbances were measured at $431 \mathrm{~nm}$. Same procedure was applied for the BCG then absorbances were measured at $444.80 \mathrm{~nm}$. It was found that drug with BCG and BCP gave maximum absorbance at $2 \mathrm{ml}$ of dye concentration. The effect of concentration of dye shown in below (Fig.6).

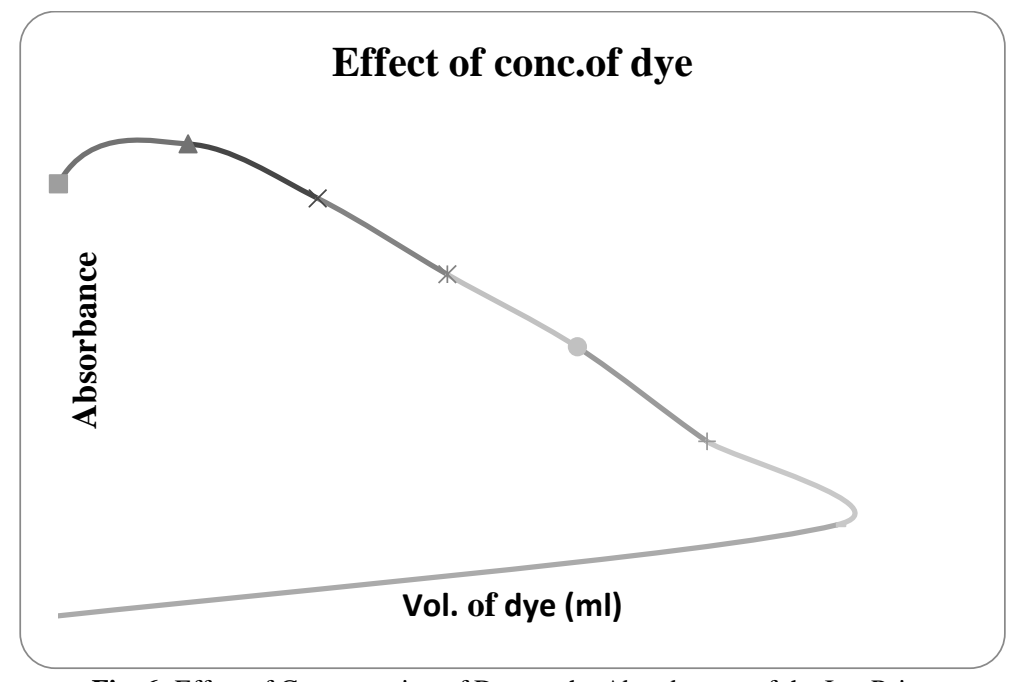

Fig. 6: Effect of Concentration of Dye on the Absorbances of the Ion-Pairs.

\subsection{Recovery studies and validation of the methods according to ICH guidelines}

Recovery study for the method was done by addition of known quantity of standard drug solution to preanalysed sample at three different concentration levels. Results for recovery study are reported in the table 1. [10-13]

Table 1: Analysis of PRG in Capsules for BCP Method (Each Capsule Contains $75 \mathrm{Mg}$ )

\begin{tabular}{lllll}
\hline Brand & Labeled Amount $(\mathrm{mg})$ & Amount found ${ }^{\mathrm{a}}(\mathrm{mg}) \pm$ SD & \% RSD & Recovery $(\%)$ \\
\hline Neugaba-75 & 75 & $75.032 \pm 0.138$ & 0.183 & 100.045 \\
Gabafit-75 & 75 & $75.06 \pm 0.184$ & 0.245 & 100.09 \\
\hline
\end{tabular}

a: average of four readings.

\section{Results and discussion}

During the course of study, it was observed that acidic solution of the drug formed coloured ion-association complexes with bromocresol purple and bromocresol green which were soluble in chloroform. This property of the drug was followed for the development of colorimetric methods for analysis of drug. The present study describes two alternative methods for the assay of PRG in capsules using BCP and BCG as the dye reagents. PRG as a positively charged amino compound in acidic medium, formed yellow coloured ion- pair complexes with negatively charged counter ions of BCP and BCG. The absorption curves of the complexes extracted into chloroform showed maxima at $431 \mathrm{~nm}$ and $444.80 \mathrm{~nm}$, respectively (Fig. 4 and 5).

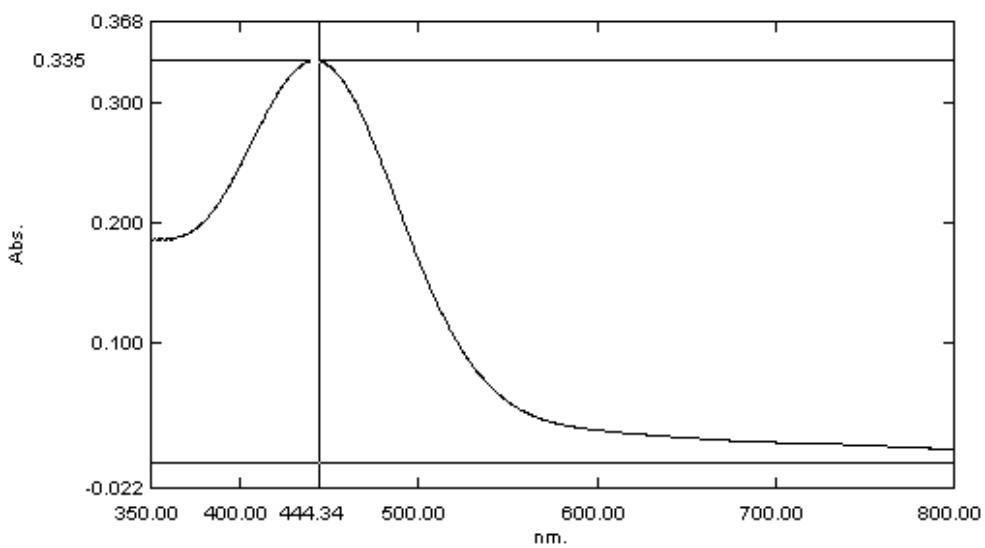

Fig. 4: Colorimetric Scan of Drug-BCP Complex. 


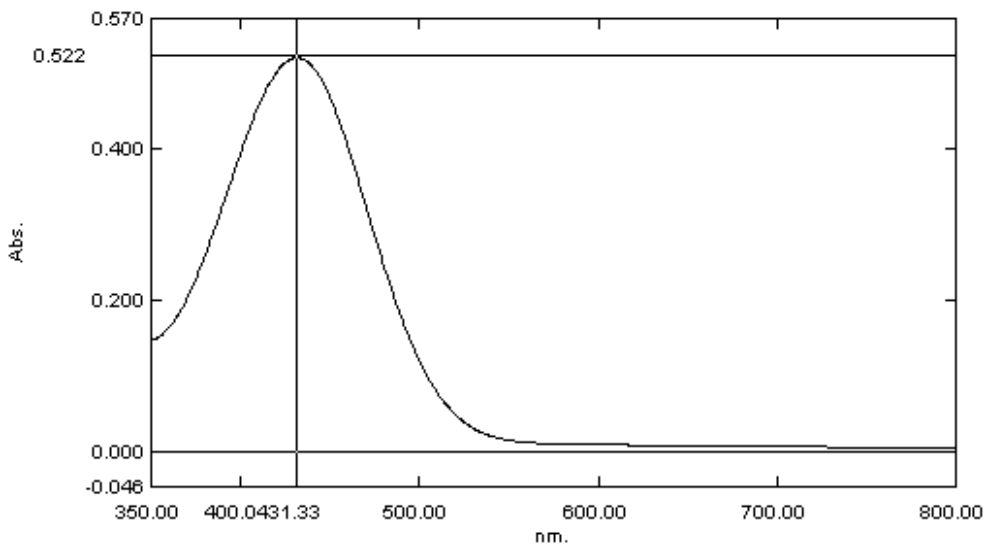

Fig. 5: Colorimetric Scan of Drug-BCG Complex.

A number of immiscible organic solvents were examined to extract the ion-pair complexes from the reaction mixtures. Chloroform was preferred for its effective and selective extraction and a shaking time of 2 minutes was found optimum to achieve a quantitative recovery of the complexes.

The extracted ion-pairs were stable for 24 hours at room temperature in the dark. The $2 \mathrm{ml}$ of reagent is sufficient for maximum yield of the reactions to PRG. It was found that under the described experimental conditions, calibration curves for two methods were constructed and Table-I. The beer's law range of the drug ranges between $10-50 \mu \mathrm{g} / \mathrm{ml}$ for both methods. The graphs are described by the regression equation, $y=a x+b$ (where $y$ is the absorbance of $1 \mathrm{~cm}$ layer, $\mathrm{a}$ is the slope, $\mathrm{b}$ is the intercept and $\mathrm{x}$ is the concentration of the measured solution in the $\mu \mathrm{g} / \mathrm{ml}$ ). The correlation coefficients 0.998 with BCP and 0.9994 with BCG indicate good linearity for the methods Fig.2 and 3, respectively. The limits of detection (LOD) and quantification (LOQ) compiled in Table 1 is indicative of the high sensitivity of the proposed method. The LOD and LOQ were calculated using LOD $=3.3 \sigma / \mathrm{S}$ and LOQ $=10 \sigma / \mathrm{S}$, where $\sigma$ is the standard deviation of seven blank determinations and $\mathrm{S}$ is the slope of the calibration curve. The proposed two methods were applied to the determination of PRG in its commercial capsules and satisfactory results were obtained (Table 2 for BCP and Table 3 for BCG method).

Table 2: Optical Characteristics and Statistical Data

\begin{tabular}{|c|c|c|}
\hline Parameters & $\mathrm{BCP}$ & BCG \\
\hline$\lambda \max (\mathrm{nm})$ & 431 & 444.80 \\
\hline Beer's law range $(\mu \mathrm{g} / \mathrm{ml})$ & $10-50$ & $10-50$ \\
\hline Molar Absorptivity (lit/mol crn ${ }^{-1}$ ) & $2.7 \times 10^{3}$ & $1.7 \times 10^{3}$ \\
\hline Sandell's sensitivity ( $\mathrm{mg} / \mathrm{ml} / 0.001$ abs units) & 0.0574 & 0.089 \\
\hline Detection limit $(\mu \mathrm{g} / \mathrm{ml})$ & 0.684 & 0.039 \\
\hline Quantification limit $(\mu \mathrm{g} / \mathrm{ml})$ & 2.075 & 0.119 \\
\hline \multicolumn{3}{|l|}{ Regression equation } \\
\hline Slope (a) & 0.0161 & 0.0083 \\
\hline Intercept (b) & 0.0185 & 0.0824 \\
\hline Correlation coefficient $\left(\mathrm{r}^{2}\right)$ & 0.998 & 0.9994 \\
\hline
\end{tabular}

$\mathrm{Y}^{\mathrm{a}}=\mathrm{a}+\mathrm{bX}$ Where $\mathrm{Y}$ is the absorbance in a cell of $10 \mathrm{~mm}$ path length and $\mathrm{X}$ is concentration in $\mu \mathrm{g} / \mathrm{ml}$.

Table 3: Analysis of PRG In Capsules for BCG Method (Each Capsule Contains $75 \mathrm{Mg}$ )

\begin{tabular}{|c|c|c|c|c|}
\hline Brand & Labeled Amount (mg) & Amount found ${ }^{\mathrm{a}}(\mathrm{mg}) \pm \mathrm{SD}$ & $\%$ RSD & Recovery (\%) \\
\hline Neugaba-75 & 75 & $74.88 \pm 0.289$ & 0.385 & 99.85 \\
\hline Gabafit-75 & 75 & $74.83 \pm 0.215$ & 0.287 & 99.775 \\
\hline
\end{tabular}

a: average of four readings.

\section{Conclusion}

The reproducibility, repeatability and accuracy of these methods were found to be good, which is evidenced by low standard deviation. The results are in good agreement with labeled value. The percentage recovery obtained indicates non interference from the common excipients used in the formulations. The proposed extractive spectrophotometric methods are rapid, sensitive, accurate and economic. Therefore they can be recommended in routine analysis of PRG in bulk and pharmaceutical formulations.

\section{Acknowledgement}

Bharathi College of pharmacy. Sun pharmaceutical ltd., Mumbai, India, for providing gift sample of Pregabalin for research.

\section{References}

[1] ARMAĞAN Ö. Development and validation of selective spectrophotometric methods for the determination of pregabalin in pharmaceutical preparation. Chinese Journal of Chemistry. 2009 Apr;27(4):781-6. https://doi.org/10.1002/cjoc.200990130.

[2] Onal A, Sagirli O. Spectrophotometric and spectrofluorimetric methods for the determination of Pregabalin in bulk and pharmaceutical preparation. Spectrochimica Acta Part A: Molecular and Biomolecular Spectroscopy. 2009 Feb 1;72(1):68-71. https://doi.org/10.1016/j.saa.2008.08.009.

[3] Jadhav AS, Pathare DB, Shingare MS. Validated enantioselective LC method, with precolumn derivatization with Marfey's reagent, for analysis of the antiepileptic drug Pregabalin in bulk drug samples. Chromatographia. 2007 Feb 1;65(3-4):253-6. https://doi.org/10.1365/s10337-006-0152-z.

[4] Vermeij TA, Edelbroek PM. Simultaneous high-performance liquid chromatographic analysis of Pregabalin, gabapentin and vigabatrin in human serum by precolumn derivatization with o-phtaldialdehyde and fluorescence detection. Journal of Chromatography B. 2004 Oct 25;810(2):297-303. https://doi.org/10.1016/S1570-0232(04)00662-2. 
[5] Mandal U., Sarkar K.A., Gowda K.V., Agarwal S., Bose A., Bhaumik U., Ghosh D., Pal T.K., Journal of Chromatographia, 67(3-4), (2008) 237-243. https://doi.org/10.1365/s10337-007-0440-2.

[6] Vaidya VV, Yetal SM, Roy SM, Gomes NA, Joshi SS. LC-MS-MS Determination of Pregabalin in human plasma. Chromatographia. 2007 Dec 1;66(11-12):925-8. https://doi.org/10.1365/s10337-007-0430-4.

[7] Zhang Y, Holliman C, Tang D, Fast D, Michael S. Development and validation of a direct Enantiomeric separation of Pregabalin to support isolated perfused rat kidney studies. Journal of Chromatography B. 2008 Nov 1;875(1):148-53. https://doi.org/10.1016/j.jchromb.2008.07.042

[8] Schelkun RM, Yuen PW, Wustrow DJ, Kinsora J, Su TZ, Vartanian MG. Heteroaromatic side-chain analogs of Pregabalin. Bioorganic \& medicinal chemistry letters. 2006 May 1;16(9):2329-32. https://doi.org/10.1016/j.bmcl.2005.06.090.

[9] Indian Pharmacopoeia, CBS publishers, II volume, 1996, A-144-5.

[10] Internationl Conference on Harmonized, guideline on validation procedure, definition terminology federal register. 1995, 60:11260.

[11] The United States of Pharmacopoeia (USP 24), Asian edition, published by the United States Pharmacopeial convention, Inc USA 2000.

[12] P.D.Sethi "HPLC quantitative analysis of pharmaceutical formulations" Third edition, CBS Publications, India, 2001 ; 53-64.

[13] Lloyd R. Snyder, Joseph L. Glajch, "Practical HPLC method Development” second edition, Wiley Interscience, New York, 685-712.

[14] Adlin J.N., Jose G.B., Tamizhmani T., Validative extractive spectrophotometric estimation of Nicorandil in tablet dosage form. Indian Drugs, 45 (7), 2008, 581-583.

[15] Patel J.M., Talele G.S., Fursule R.A., Surana S.J., Extractive Spectrophotometric determination of Desloratidine from its bulk and pharmaceutical dosage form. Indian Drugs, 43(6), (2006), 507-509.

[16] Gurupadayya B.M., Vijaya B.V., Manohara Y.N., Prasad R.D.V., Heamalatha S., Spectrophotometric methods for the estimation of Amrinone Lactate in Bulk and Pharmaceutical Formulation. Indian Drugs, 45 (3), (2008), 193-198. 